\title{
The Effect of Long-Term Usage of Single-Agent Antiglaucomatous Drops with Different Preservatives on Cornea Biomechanics
}

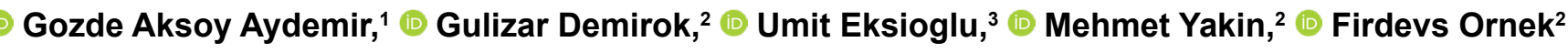 \\ 'Department of Ophthalmology, Adiyaman University Training and Research Hospital, Adiyaman, Turkey \\ 2Department of Ophthalmology, Health Sciences University, Ankara Training and Research Hospital, Ankara, Turkey \\ ${ }^{3}$ Department of Ophthalmology, Baskent University Ankara Hospital, Ankara, Turkey
}

\begin{abstract}
Objectives: This study examined the effect of antiglaucomatous drops with different preservatives on corneal biomechanics using the ocular response analyzer (ORA) (Reichert Technologies, Inc., Depew, NY, USA).

Methods: Patients using antiglaucomatous medical treatment containing a single agent combined with a preservative for at least I year who underwent a control examination between January and December 2017 at a glaucoma unit were included in this retrospective study. The patients were divided into 5 groups according to the antiglaucomatous agent and preservative ingredients. Measurements were taken with the ORA and compared with a control group.

Results: A total of 83 eyes treated eyes were included and analyzed. Thirty-three eyes of 33 patients were treated with latanoprost+benzalkonium chloride (BAC), 17 eyes of 17 patients were treated with travoprost+polyquad, 7 eyes of 7 patients were treated with bimatoprost+BAC, 18 eyes of 18 patients were treated with brimonidine+purite, 8 eyes of 8 patients were treated with brimonidine+BAC. A control group of 23 eyes of 23 healthy patients was also assessed for comparison. A significant decrease in corneal hysteresis $(\mathrm{CH})$ and corneal resistance factor (CRF) was seen in the patients using bimatoprost+BAC and brimonidine+BAC when compared with the control group. Evaluation of the bimatoprost+BAC group and the latanoprost+BAC group revealed that the $\mathrm{CH}$ and the $\mathrm{CRF}$ was significantly lower in the group using bimatoprost+BAC $(p<0.01)$.

Conclusion: It has been reported that $\mathrm{CH}$ is a more important prognostic marker than central corneal thickness in glaucoma patients. Loss of visual field progresses faster in eyes with a low $\mathrm{CH}$. Both preservatives and the active antiglaucomatous agents in medications can affect $\mathrm{CH}$. Variation in $\mathrm{CH}$ in patients using antiglaucomatous drops over a long period is important in both the progression and follow-up of the disease.
\end{abstract}

Keywords: Antiglaucomatous drops, benzalkonium chloride, cornea biomechanics, ocular response analyzer, polyquad, purite.

\section{Introduction}

Glaucoma is second only to cataracts as the most common cause of blindness in the world. At present, topical antiglaucomatous medications continue to be the first-line treatment, although other options for the treatment of glaucoma have been presented in the literature. Toxic ocular reactions following long-term use of topical medication may cause drug intolerance and side effects. Effects experienced due to the active substance of the drug or the added preservative substances are considered a potential source of reduced use

How to cite this article: Aksoy Aydemir G, Demirok G, Eksioglu U, Yakin M, Ornek F. The Effect of Long-Term Usage of Single-Agent Antiglaucomatous Drops with Different Preservatives on Cornea Biomechanics. Beyoglu Eye J 202I; 6(I): 24-30.

Address for correspondence: Gozde Aksoy Aydemir, MD. Adiyaman Universitesi Egitim ve Arastirma Hastanesi Oftalmoloji Bolumu, Adiyaman, Turkey

Phone: +90 5532293332 E-mail: gzdaksoy@hotmail.com

Submitted Date: August 28, 2020 Accepted Date: January 08, 2021 Available Online Date: February 15, 2021

${ }^{\circ}$ Copyright 2020 by Beyoglu Eye Training and Research Hospital - Available online at www.beyoglueye.com OPEN ACCESS This work is licensed under a Creative Commons Attribution-NonCommercial 4.0 International License. 
compliance, one the biggest challenges in the medical treatment of glaucoma and eye complaints $(I, 2)$.

Long-term use of topical drugs has clearly been shown to induce toxic immunopathological changes in the ocular surface (3). Antiglaucomatous drugs containing pilocarpine and beta-blockers have been shown to cause ocular reactions; however, preservative agents (e.g., benzalkonium chloride $[B A C])$ have also been shown to have toxic effects on the corneal epithelium, conjunctiva and tear function, the trabeculum, and endothelial cells (4-6).

The risk of subconjunctival fibrosis increases in patients who use topical drops with preservative agents over a long period, and bleb life is reduced in glaucoma surgery (7). It is important to reduce the toxic load on ocular tissues resulting from long-term use of preservative agents. Currently, there is a preference for antiglaucomatous drops containing preservatives known to have fewer side effects and disposable preparations with no preservatives.

The ocular response analyzer (ORA) (Reichert Technologies, Inc., Depew, NY, USA) is a device developed in 2005 to measure the biomechanical properties of corneas. The ORA evaluates corneal hysteresis $(\mathrm{CH})$ and the corneal resistance factor (CRF). It measures intraocular pressure (IOP) without direct corneal contact using a stream of air. The cornea responds to the force of the air pulse with a concave deformation and then relaxes and returns to normal curvature. $\mathrm{CH}$ and CRF refers to biomechanical properties of the cornea: $\mathrm{CH}$ reflects the viscoelastic characteristics involved in the absorption and release of energy, and CRF is considered an indicator of the overall corneal resistance (8).

The aim of this study was to investigate the effect of long-term use of antiglaucomatous drops containing different preservatives on corneal biomechanics using the ORA.

\section{Methods}

Patients who had used antiglaucomatous medication containing no more than I preservative agent for at least a year were included. This retrospective study was approved by the Education, Research and Coordination Board of Ankara Training and Research Hospital (Approval Date: 10.02.2016, Approval number: 5270).

Patients were excluded if they used more than I topical antiglaucomatous medication; eye drops for dry eyes containing preservatives; wore contact lenses; had undergone ocular surgery or refractive surgery; had a history of or an active ocular infection, inflammation, or systemic disease that could affect the corneal biomechanics; had evidence of other ocular surface disease; or had a spherical equivalent value $>-3.00$ diopters. Patients with advanced stage glaucoma (mean deviation value $>-12$ ) were also excluded due to the potential effect on cornea biomechanics.
The patients were divided into 5 groups according to the agent and preservative content of the antiglaucomatous medication. The agents and preservative contents of the preparations included in the study were:

- Xalatan (latanoprost+BAC) (Pfizer Inc., New York, NY, USA)

- Travatan (travoprost+polyquad[PQ]) (Novartis Europharm Ltd., Horsham, UK)

- Lumigan (bimatoprost+BAC) (Allergan Inc., Madison, NJ, USA)

- Alphagan (brimonidin+purite) (Allergan Inc., Madison, NJ, USA)

- Brimogut (brimonidin+BAC) (Bilim Pharmaceuticals, Istanbul, Turkey)

All of the measurements were performed at the same time of day to reduce the effect of diurnal rhythm changes. The patient was seated with their forehead appropriately positioned on the device and asked to look at the infrared light sensor inside the device, and measurements were made using the dynamic air-puff system $(\mathrm{CH}, \mathrm{CRF}$, Goldmann-correlated IOP, and the corneal compensated IOP). A single physician performed all of the measurements.

The patients' demographic characteristics and diagnoses were recorded. The eye with the highest ORA reliability index was included in the study. The duration of drug use was recorded in months. The control group comprised patients of similar age and gender, with no previous anterior segment surgery, no ocular surface diseases, active ocular infection, inflammation, or systemic disease.

\section{Statistical Analysis}

The data were analyzed using IBM SPSS Statistics for Windows, Version 20.0 (IBM Corp., Armonk, NY, USA). Normal distribution of the variables was evaluated using the Shapiro-Wilk test. Mean and SD values were used as descriptive statistics. The significance of the differences between the groups was assessed using Student's t-test for 2 independent groups, and one-way analysis of variance was employed for more than 2 groups. Pearson and Spearman correlation analyses were used for normally distributed data. A $95 \%$ confidence interval was constructed and a $p$ value of $<0.05$ was considered statistically significant.

\section{Results}

The study consisted of 6 groups:

- Group I: 33 eyes of 33 patients using latanoprost+BAC for at least I year

- Group 2: 17 eyes of 17 patients using travoprost+PQ for at least I year

- Group 3: 7 eyes of 7 patients using bimatoprost+BAC for at least I year 
- Group 4: 18 eyes of 18 patients using brimonidine+purite for at least I year

- Group 5: 8 eyes of 8 patients using brimonidine+BAC for at least I year

- Control group: 23 eyes of 23 patients

The right eye of 50 patients (60.2\%) and the left eye of 33 patients $(39.8 \%)$ were included in the patient group. In the control group, the right eye of 12 patients $(52.2 \%)$ and the left eye of II patients (47.8\%) were assessed.

Of the 83 patients in the patient group, 24 were male and 59 were female. Of the 23 patients in the control group, II were male and 12 were female. The mean age of the patient group was $63.65 \pm 9.24$ years, and the mean age of the control group was $60.26 \pm 9.72$ years. The demographic characteristics of the patients are displayed in Table I.

Table I. Duration of drug use and mean age of patient groups

\section{n Duration of drug use Age (years)} (months) \pm SD

\begin{tabular}{lccc}
\hline Latanoprost+BAC & 33 & $59.57 \pm 33.85$ & $61.96 \pm 9.06$ \\
Travoprost+PQ & 17 & $59.64 \pm 35.34$ & $62.82 \pm 8.63$ \\
Bimatoprost+BAC & 7 & $68.57 \pm 22.67$ & $65.42 \pm 13.81$ \\
Brimonidin+purite & 18 & $51.33 \pm 36.36$ & $66.22 \pm 9.62$ \\
Brimonidin+BAC & 8 & $24.50 \pm 16.58$ & $65.00 \pm 5.39$ \\
Control group & 23 & & $60.26 \pm 9.72$
\end{tabular}

BAC: Benzalkonium chloride; PQ: Polyquad.
An ORA was used to record measurements of the patient group and the control group. $\mathrm{CH}$ and the CRF measurements were evaluated (Table 2 ).

The bimatoprost+BAC and the brimonidin+BAC patients groups had a lower $\mathrm{CH}$ and $\mathrm{CRF}$ compared with the control group. Comparison of the $\mathrm{CH}$ and $\mathrm{CRF}$ in other patient groups with the control group did not yield a significant difference.

The patient groups were also divided into groups defined by an active substance prostaglandin (PG) analog or an alpha-agonist and within-group comparisons were conducted. Three patient groups who used a PG analog were assessed in pairs. There were no significant differences in the $\mathrm{CH}$ and CRF between the latanoprost $+B A C$ and the travoprost $+\mathrm{PQ}$ groups (Table 3).

When the latanoprost+BAC and the bimatoprost+BAC patient groups were compared, there was a significant decrease in the $\mathrm{CH}$ and CRF values in the group using bimatoprost+BAC $(p<0.01)$ (Table 4). There were no significant differences in the $\mathrm{CH}$ and $\mathrm{CRF}$ values when the patient groups using travoprost $+\mathrm{PQ}$ and bimatoprost $+\mathrm{BAC}$ were contrasted (Table 5).

The patients using an alpha-agonist agent were also analyzed. Although there was no significant difference in the $\mathrm{CH}$ between patients using brimonidine+purite and those using brimonidine+BAC, there was a significant difference in the CRF (Table 6).

No significant differences were determined when comparing the brimonidine+BAC and bimatoprost+BAC groups.

Table 2. Comparison of the control group and patients using I active substance and different types of preservatives for at least I year

\begin{tabular}{lccccc} 
& $\mathbf{n} \dagger$ & Corneal hysteresis & $\mathbf{p}$ & Corneal resistance factor & $\mathbf{p}$ \\
\hline Latanoprost+BAC & 33 & $9.92 \pm 1.31$ & 0.38 & $10.78 \pm 1.88$ & 0.71 \\
Travoprost+PQ & 17 & $9.56 \pm 2.02$ & 0.23 & $10.20 \pm 2.21$ & 0.53 \\
Bimatoprost+BAC & 7 & $8.50 \pm 1.22$ & $\mathbf{0 . 0 1 \pm}$ & $8.77 \pm 1.81$ & $\mathbf{0 . 0 2 \pm}$ \\
Brimonidin+purite & 18 & $9.54 \pm 1.19$ & 0.12 & $11.31 \pm 1.33$ & 0.11 \\
Brimonidin+BAC & 8 & $8.77 \pm 1.21$ & $\mathbf{0 . 0 2 \pm}$ & $8.93 \pm 1.38$ & $\mathbf{0 . 0 2 \pm}$ \\
Control group & 23 & $10.26 \pm 1.64$ & & $10.60 \pm 1.75$ &
\end{tabular}

$\pm: \mathrm{p}<0.05$ considered significant; $\mathrm{n}$ †: Number of patients; BAC: Benzalkonium chloride; PQ: Polyquad.

Table 3. Comparison of patient groups using latanoprost $+B A C$ and travoprost $+P Q$

\begin{tabular}{lccc} 
& Latanoprost+BAC & Travoprost+PQ & P \\
\hline Corneal hysteresis & $9.92 \pm 1.31$ & $9.56 \pm 2.02$ & 0.45 \\
Corneal resistance factor & $10.78 \pm 1.88$ & $10.20 \pm 2.21$ & 0.33
\end{tabular}

$\pm:$ P $<0.05$ considered significant; BAC: Benzalkonium chloride; PQ: Polyquad. 
Table 4. Comparison of patient groups using latanoprost $+B A C$ and bimatoprost $+B A C$

\begin{tabular}{lccc} 
& Latanoprost+BAC & Bimatoprost+BAC & P \\
\hline Corneal hysteresis & $9.92 \pm 1.31$ & $8.50 \pm 1.22$ & 0.01 \\
Corneal resistance factor & $10.78 \pm 1.88$ & $8.77 \pm 1.81$ & 0.01 \\
\hline$\pm: p<0.05$ considered significant; BAC: Benzalkonium chloride. & & \\
\hline
\end{tabular}

Table 5. Comparison of patient groups using travoprost $+P Q$ and bimatoprost $+B A C$

\begin{tabular}{lccc} 
& Travoprost+PQ & Bimatoprost+BAC & P \\
\hline Corneal hysteresis & $9.56 \pm 2.02$ & $8.50 \pm 1.22$ & 0.21 \\
Corneal resistance factor & $10.20 \pm 2.21$ & $8.77 \pm 1.81$ & 0.14 \\
\hline
\end{tabular}

$\pm:$ p $<0.05$ considered significant; BAC: Benzalkonium chloride; PQ: Polyquad.

Table 6. Comparison of patient groups using brimonidin+purite and brimonidin+BAC

\begin{tabular}{lccc} 
& Brimonidin+purite & Brimonidin+BAC & P \\
\hline Corneal hysteresis & $9.54 \pm 1.19$ & $8.77 \pm 1.21$ & 0.14 \\
Corneal resistance factor & $11.31 \pm 1.33$ & $8.93 \pm 1.38$ & 0.00 \\
\hline$\pm: p<0.05$ considered significant; BAC: Benzalkonium chloride. & & \\
\hline
\end{tabular}

Table 7. The duration of drug use and the relationship between $\mathrm{CH}$ and $\mathrm{CRF}$

\begin{tabular}{lccc} 
& Duration of drug use (months) & CH; p & CRF; p \\
\hline Latanoprost+BAC & $59.57 \pm 33.85$ & 0.34 & 0.70 \\
Travoprost+PQ & $59.64 \pm 35.34$ & 0.07 & $0.01^{*}$ \\
Bimatoprost+BAC & $68.57 \pm 22.67$ & 0.14 & 1 \\
Brimonidin+purite & $51.33 \pm 36.36$ & 0.58 & 0.83 \\
Brimonidin+BAC & $24.50 \pm 16.58$ & 0.80 & 0.62 \\
\hline
\end{tabular}

$\pm:$ p 0.05 considered significant; BAC: Benzalkonium chloride; $\mathrm{CH}$ : Corneal hysteresis; $\mathrm{CRF}$ : Corneal resistance factor; PQ: Polyquad.

Both medications contained the same concentration of BAC.

Relationships between the duration of drug use and the duration of $\mathrm{CH}$ and $\mathrm{CRF}$ changes were also investigated. Spearman's rho analysis determined a significant $p$ value for only the travoprost+PQ group (Table 7). There was a moderately negative correlation between the length of use in the travoprost+PQ group and the CRF (rho: -0.58 ). There was also a negative relationship the $\mathrm{CH}$ value, though it was not statistically significant.

\section{Discussion}

The first approach to the treatment of glaucoma is the use of IOP-lowering drugs (antiglaucomatous agents). Though there are a variety of antiglaucomatous drugs, PG analogs are generally the first choice. PG analogs are very potent, have few systemic or local side effects, and can provide an adequate reduction in pressure with a single daily application. If the response to PG treatment is insufficient, other agents (beta-blockers, carbonic anhydrase inhibitors, alpha-2 agonists) can be added to the treatment. Occasionally, 3 or more molecules may be required for IOP control (9).

Corneal tissue demonstrates viscoelastic properties in response to the pressure applied during IOP measurement. The cornea absorbs and then dissipates energy as heat as it returns to the original position (I0). This characteristic led to the emergence of corneal biomechanical parameters 
other than central corneal thickness (CCT). The ORA is a noncontact tonometer that can measure new biomechanical parameters expressing the viscoelastic properties of the cornea, such as the $\mathrm{CH}$ and CRF (8). Studies have shown that $\mathrm{CH}$ can have a diurnal variation (8).

Research has also indicated that IOP can cause an increase in $\mathrm{CH}$. lordanidou et al.(I I) performed deep sclerotomy+collagen implants in 30 patients and compared findings of the pre- and postoperative $\mathrm{I}^{\text {st }}, 8^{\text {th }}$, and $30^{\text {th }}$ days. They showed that the $\mathrm{CH}$ had increased during the follow-up period. In a study by Sun et al.,(I2) it was demonstrated that the $\mathrm{CH}$ of 40 patients with chronic angle-closure glaucoma had elevated from $6.80 \pm 2.08 \mathrm{mmHg}$ to $9.22 \pm 1.80 \mathrm{mmHg}$ in the second week with a decrease in IOP after medical \pm surgical treatment.

$\mathrm{CH}$ measurement is important in glaucoma since a low $\mathrm{CH}$ is a factor in progression of the disease. Susanna et al. (13) reported that of 287 eyes of 199 patients, 54 had developed visual field loss after 4 years of follow-up. They found lower basal $\mathrm{CH}$ values in these 54 eyes (p: 0.01). Each I $\mathrm{mmHg}$ decrease in $\mathrm{CH}$ has been shown to increase the risk of glaucoma by $21 \%$ (I3).

Medeiros et al.(14) reported similar results. In their study of 114 eyes of 68 patients, every $1 \mathrm{mmHg}$ decrease in IOP was found to be proportional to the loss of $0.25 \%$ per year in visual field index using univariate models with only $\mathrm{CH}$ as a predictive factor $(\mathrm{p}<0.00 \mathrm{I})$. In eyes with a low $\mathrm{CH}$ value, visual field loss progresses faster.

In another study, De Moraes et al.(I5) investigated the importance of $\mathrm{CH}$ and $\mathrm{CCT}$ in disease progression. The findings suggested that progression was faster in patients with a low $\mathrm{CH}$ and a low CCT. According to multiple analyses, $\mathrm{CH}$ was more greatly associated with progression than CCT.

In this study, we investigated the effects of preservative agents in antiglaucomatous drops on corneal biomechanics. In many in vivo and in vitro studies, preservative agents have been shown to have toxic effects on the cornea. Hjunjoo et al.(16) reported that drops containing BAC increased the presence of proinflammatory cytokines such as interleukin 6 on the corneal surface, decreased goblet cell count in the conjunctiva, and increased lymphocytic infiltration in rabbit eyes.

Liang et al.(17) noted that as the concentration of BAC increased during repeated drug exposure, cytotoxicity increased in the rabbit corneal epithelium, and that tafluprost without preservatives was better tolerated than the other PG analog drugs containing BAC.

Ammar et al.(18) reported that tafluprost containing $0.01 \%$ BAC resulted in more severe cytotoxicity in conjunctival epithelium cells than $0.01 \%$ BAC alone. In contrast, travoprost with $0.01 \%$ BAC produced less cytotoxicity than $0.01 \%$ BAC alone. The authors concluded that travoprost reduced BAC toxicity. Furthermore, BAC-related toxicity also suggested that PG analogs may have an effect on increasing or decreasing this toxicity.

To the best of our knowledge, there is no previous study in the literature that has examined how preservative agents affect corneal biomechanics. We used 5 groups of drugs with a single active agent and different preservatives and compared the ORA results of patients who had been using the drugs for at least 12 months with a control group and within the treatment groups.

We determined no relationship between the mean duration of drug use and the change in $\mathrm{CH}$ and CRF in the latanoprost+BAC group. The $\mathrm{CH}$ values were lower than those of the control group, but without statistical significance.

The mean duration of drug use in patients using the travoprost $+\mathrm{PQ}$ preparation was negatively correlated with the CRF. We found that the decrease in the CRF was moderately significant as the duration of use increased. Although the impact of the duration of drug use on $\mathrm{CH}$ was more meaningful than in the other groups, it was not statistically significant. This suggests a decrease in the $\mathrm{CH}$ and $\mathrm{CRF}$ as the duration of drug usage increases. This is important in terms of glaucoma progression. When compared with the control group, no significant difference was found in the $\mathrm{CH}$ and $\mathrm{CRF}$.

There was no relationship between the mean duration of drug use and the $\mathrm{CH}$ and CRF changes in the bimatoprost+BAC patient group. When compared with the control group, the $\mathrm{CH}$ and CRF were lower than those of the control group. While there was no significant difference between the patient group who used latanoprost with a higher $B A C$ concentration and the control group, the patients using bimatoprost+BAC had lower $\mathrm{CH}$ and CRF values than the control group. It may be that the effect of the active agents is more significant than that of the preservatives on corneal biomechanics. The manufacturer reduced the concentration of bimatoprost in the next generation product. Figus et al.(19) observed that $\mathrm{CH}$ decreased in 60 patients who had used $0.03 \%$ bimatoprost and subsequently converted to a $0.01 \%$ bimatoprost preparation. In addition, they reported that goblet cell density increased from 350 cells $/ \mathrm{mm} 2$ to 425.5 cells $/ \mathrm{mm} 26$ months after the drug exchange. This suggests that the decrease in $\mathrm{CH}$ and $\mathrm{CRF}$ may have been related to a high bimatoprost concentration in our study. Under these conditions, the effects of the PG agents and the preservative agents cannot be divided into the boundaries on the ORA.

Ammar et al.(18) reported that PG analogs may have the effect of increasing or decreasing BAC-related toxicity. It is important to note here that different drugs, even from the same family of drugs, act differently on the cornea and have different corneal biomechanical effects. 
Another important point is that we observed no difference in the $\mathrm{CH}$ and $\mathrm{CRF}$ between the bimatoprost+BAC and brimonidine+BAC groups, and both preparations contained the same measure of BAC. We compared these 2 groups of patients in the correlation analysis because there was no relationship between the duration of drug use and $\mathrm{CH}$ and the CRF. Due to the large number of limiting factors, the small number of patients is not sufficient to provide reliable advantages/disadvantages.

When the patient groups who used $0.15 \%$ brimonidin $+0.05 \mathrm{mg} / \mathrm{mL}$ BAC and $0.15 \%$ brimonidin $+0.005 \%$ purite were compared, the $\mathrm{CH}$ was lower in the $0.15 \%$ brimonidin $+0.05 \mathrm{mg} / \mathrm{mL}$ BAC group, but without statistical significance. The CRF was also lower in the group using $0.15 \%$ brimonidin $+0.05 \mathrm{mg} / \mathrm{mL}$ BAC. The limiting aspect is the lack of patients using $0.15 \%$ brimonidin $+0.05 \mathrm{mg} / \mathrm{mL}$ BAC. Several studies have shown that BAC is more cytotoxic than purite.

Another point of note in this study is the ORA reliability index (wavefront score). This parameter was included by the manufacturer, but a threshold value was not specified. There are several studies on this subject. Marcelo et al.(20) evaluated 226 eyes to analyze the reliability index of the ORA. Based on the correlation between IOP measured by the ORA and IOP measured by applanation, the cutoff value for the reliability index was determined to be 7 .

Our study is believed to be the first in the literature to examine and provide data related to the effects on corneal biomechanics of long-term use of preservative agents. The average follow-up period of patients using a PG analog was about 5 years. A limitation of our study is the small number of patients, particularly in the bimatoprost+BAC group, due to the exclusion criteria applied.

$\mathrm{CH}$ tends to decrease with age in glaucoma patients. This physiological process to normalize the contrast to accelerate the antiglaucomatous agent serves the primary goal in terms of the progression of glaucoma. Visual field loss occurs more quickly in glaucoma patients with a low $\mathrm{CH}$. Research has indicated that the $\mathrm{CH}$ increases with a decrease in IOP after surgical or medical treatment in glaucoma patients.

Although the bimatoprost+BAC group had lower $\mathrm{CH}$ and $\mathrm{CRF}$ values than the control group, the latanoprost+BAC group values were not significantly different. This may be due to the high bimatoprost concentration used in the bimatoprost+BAC group. This has been reduced by one-third in the latest generation product. However, the fact that the brimonidine+BAC group had lower $\mathrm{CH}$ and $\mathrm{CRF}$ values than the control group suggests that the BAC molecule affects corneal biomechanics. Nonetheless, the effect of the active substance can't be disregarded. In addition, when the brimonidine+BAC patient group and the brimonidine+purite patient group were compared, the statistically not significant low $\mathrm{CH}$ value of the brimonidine+BAC group does not support our hypothesis.

\section{Conclusion}

Glaucoma patients must often use antiglaucomatous drops for a long period of time. The active agents and preservatives in these drops may affect the $\mathrm{CH}$. $\mathrm{CH}$ is more important than CCT in glaucoma progression. It is important to monitor changes in the $\mathrm{CH}$ in patients who use antiglaucomatous drops. Agents that do not contain preservatives or their active ingredients should be preferred in order to reduce the effect on the treatment process.

\section{Disclosures}

Ethics Committee Approval: This retrospective study was approved by the Education, Research, and Coordination Board of Ankara Training and Research Hospital on July 4, 2017 (no: 8233).

Peer-review: Externally peer-reviewed.

Conflict of Interest: None declared.

Authorship Contributions: Involved in design and conduct of the study (GAA, GD); preparation and review of the study (UE, MY, FO); data collection (GAA, GD, UE); and statistical analysis (GAA, MY).

\section{References}

I. Broadway DC, Grierson I, O'Brien C, Hitchings RA. Adverse effects of topical antiglaucoma medication. I. The conjunctival cell profile. Arch Ophthalmol 1994; I 2: 1437-45. [CrossRef]

2. Yalvaç IS, Gedikoğlu G, Karagöz Y, Akgün U, Nurözler A, Koç $\mathrm{F}$, et al. Effects of antiglaucoma drugs on ocular surface. Acta Ophthalmol Scand 1995;73:246-8. [CrossRef]

3. Arici MK, Arici DS, Topalkara A, Güler C. Adverse effects of topical antiglaucoma drugs on the ocular surface. Clin Exp Ophthalmol 2000;28: I I3-7. [CrossRef]

4. Baudouin C, Pisella PJ, Fillacier K, Goldschild M, Becquet F, De Saint Jean $M$, et al. Ocular surface inflammatory changes induced by topical antiglaucoma drugs: human and animal studies. Ophthalmology 1999;106:556-63. [CrossRef]

5. van Beek LM, de Keizer RJ, Polak BC, Elzenaar PR, van Haeringen NJ, Kijlstra A. Incidence of ocular side effects of topical beta blockers in the Netherlands. Br J Ophthalmol 2000;84:856-9.

6. Baudouin C, Denoyer A, Desbenoit N, Hamm G, Grise A. In vitro and in vivo experimental studies on trabecular meshwork degeneration induced by benzalkonium chloride (an American Ophthalmological Society thesis). Trans Am Ophthalmol Soc 2012;110:40-63.

7. Sherwood MB, Grierson I, Millar L, Hitchings RA. Long-term morphologic effects of antiglaucoma drugs on the conjunctiva and Tenon's capsule in glaucomatous patients. Ophthalmology 1989;96:327-35. [CrossRef]

8. Luce DA. Determining in vivo biomechanical properties of the cornea with an ocular response analyzer. J Cataract Refract 
Surg 2005;31:156-62. [CrossRef]

9. Doğanay S, Çankaya C. Glokom ilaçlarının gelişimi ve ilaç tedavi prensipleri. Glokom-Katarakt Dergisi 2010;5:179-85.

10. Brown KE, Congdon NG. Corneal structure and biomechanics: impact on the diagnosis and management of glaucoma. Curr Opin Ophthalmol 2006; 17:338-43. [CrossRef]

II. lordanidou V, Hamard P, Gendron G, Labbe A, Raphael M, Baudouin $C$. Modifications in corneal biomechanics and intraocularpressure after deep sclerectomy. J Glaucoma 2010;19:252-6.

12. Sun L, Shen M, Wang J, Fang A, Xu A, Fang H, et al. Recovery of corneal hysteresis after reduction of intraocular pressure in chronic primary angleclosure glaucoma. Am J Ophthalmol 2009; 147:1061-6, 1066.el-2. [CrossRef]

13. Susanna CN, Diniz-Filho A, Daga FB, Susanna BN, Zhu F, Ogata $N G$, et al. A prospective longitudinal study to investigate cor neal hysteresis as a risk factor for predicting development of glaucoma. Am J Ophthalmol 2018;187:148-52. [CrossRef]

14. Medeiros FA, Meira-Freitas D, Lisboa R, Kuang TM, Zangwill LM, Weinreb RN. Corneal hysteresis as a risk factor for glaucoma progression: a prospective longitudinal study. Ophthalmology 2013;120:1533-40. [CrossRef]

15. De Moraes CV, Hill V, Tello C, Liebmann JM, Ritch R. Lower corneal hysteresis is associated with more rapid glaucomatous visual field progression. J Glaucoma 2012;21:209-13. [CrossRef]

16. Lee HJ, Jun RM, Cho MS, Choi KR. Comparison of the ocular surface changes following the use of two different prostaglandin F2- analogues containing benzalkonium chloride or polyquad in rabbit eyes. Cutan Ocul Toxicol 2015;34:195-202. [CrossRef]

17. Liang H, Brignole-Baudouin F, Pauly A, Riancho L, Baudouin C. Polyquad-preserved travoprost/timolol, benzalkonium chloride (BAK)-preserved travoprost/timolol, and latanoprost/timolol in fixed combinations: a rabbit ocular surface study. Adv Ther 201।;28:3। I-25. [CrossRef]

18. Ammar DA, Noecker RJ, Kahook MY. Effects of benzalkonium chloride-preserved, $\mathrm{PQ}$-preserved, and sofZia-preserved topical glaucoma medications on human ocular epithelial cells. Adv Ther 2010;27:837-45. [CrossRef]

19. Figus M, Nardi M, Piaggi P, Sartini M, Guidi G, Martini L, et al. Bimatoprost $0.01 \%$ vs bimatoprost $0.03 \%$ : a 12 -month prospective trial of clinical and in vivo confocal microscopy in glaucoma patients. Eye (Lond) 20I4;28:422-9. [CrossRef]

20. Ayala M, Chen E. Measuring corneal hysteresis: threshold estimation of the wavefrom score from the Ocular Response Analyzer. Cornea 2012;250:1803-6. [CrossRef] 